\title{
A Case of Congenital Bifurcation of the Labyrinthine Segment of Facial Nerve
}

\author{
Il-Gye Lim, $\mathrm{MD}^{1}$, Seoung-Min Lee, $\mathrm{MD}^{1}$ and Dong-Hee Lee, $\mathrm{MD}, \mathrm{PhD}^{1,2}$ \\ ${ }^{I}$ Department of Otolaryngology-Head and Neck Surgery, College of Medicine, The Catholic University of Korea, \\ Seoul; and ${ }^{2}$ Department of Otolaryngology-Head and Neck Surgery, Uijeongbu St. Mary's Hospital, \\ The Catholic University of Korea, Seoul, Korea
}

\begin{abstract}
- ABSTRACT -
The most common anomaly of facial nerve is bony dehiscence of the fallopian canal, being present in approximately $55 \%$ of the population. Abnormal courses of facial nerve are reported commonly. Of the malformation of the facial nerve, bifurcation of its intratemporal portion has been rarely reported, in which one or more segments of the facial nerve splits. Nine years-old girl (right-handed) came to our outpatient clinic for left hearing loss, which was incidentally found by herself. Audiologic and radiologic work-up demonstrated unilateral sensorineural hearing loss, which was resulted from the narrow bony cochlear nerve canal, and incidentally found the bifurcation of the labyrinthine segment of ipsilateral facial nerve. We described characteristic findings on the computed tomogram of this anomaly and discussed it. It is important to identify the anomalous facial nerve in the patients undergoing evaluation for congenital hearing loss. (J Clinical Otolaryngol 2019;30:83-87)
\end{abstract}

KEY WORDS : Fallopian canal $\cdot$ Labyrinthine segment $\cdot$ Facial nerve $\cdot$ Variation $\cdot$ Congenital abnormalities.

\section{Introduction}

Although many congenital anomalies of the ear or syndrome including them present the possibility of anomalous facial nerve, isolated variations in facial nerve anatomy can occur. Consequently, it is important for the otologist to know many variations or anomalies of the facial nerve. Of various anomalies of the facial nerve anatomy, congenital bony dehiscence of the fallopian canal is the most common abnormality encountered.

Thorough understanding of anatomical variations of the facial nerve is very important, because the facial nerve anomalies are usually accompanied by the

논문접수일 : 2019년 2월 19일

논문수정일 : 2019년 3월 28일

심사완료일 : 2019년 4월 22일

교신저자 : 이동희, 11765 경기도 의정부시 천보로 271

가톨릭대학교 의과대학 의정부성모병원 이비인후과학교실

전화 : (031) 820-3564·전송 : (031) 847-0038

E-mail:leedh0814@catholic.ac.kr middle and inner ear malformations. ${ }^{1,2)}$ Bifurcation or duplication of the facial nerve can be found in any segment of the facial nerve and is most commonly found in its tympanic segment. ${ }^{3,4)}$ On the other hand, bifurcation of the labyrinthine segment is reported as the rarest of the facial nerve anomalies. Glastonbury et al. ${ }^{2}$ stated that Nager's citation of two German articles was only English language reports of labyrinthine bifurcations. Here, we describe a case of bifurcation of labyrinthine segment of the facial nerve in 9-year old girl, which was accompanied by the narrow bony cochlear nerve canal.

\section{Case Report}

A 9-year old girl came to the outpatient clinic to evaluate her hearing level with 1-year history of left hearing loss, which was detected incidentally by herself. She did not have any past medical history except for tonsillectomy and adenoidectomy, which was done at our hospital 4 years ago. There was no history of 
universal hearing screening at birth. On physical examination, tympanic membrane and external auditory canal of both ears was normal and facial weakness was not found. She denied any history of tinnitus.

Pure-tone audiometry revealed that sensorineural hearing loss of four-frequency pure-tone average of $66 \mathrm{~dB}$ HL (hearing level), speech recognition threshold of $75 \mathrm{~dB}$ HL and speech discrimination score of $0 \%$ in left ear. Hearing level of right ear was within normal of four-frequency pure-tone average of $15 \mathrm{~dB}$
$\mathrm{HL}$, speech recognition threshold of $15 \mathrm{~dB} \mathrm{HL}$ and speech discrimination score of $100 \%$.

A high-resolution computed tomography (CT) of temporal bone demonstrated the narrow bony cochlear nerve canal on left side, which was pointed out as a cause of her left sensorineural hearing loss. It also showed the bifurcation of the labyrinthine segment of her left facial nerve (Fig. 1, 2). There was no finding suggestive of bony dehiscent fallopian canal in this case. Using a PACS (Picture archiving and communi-
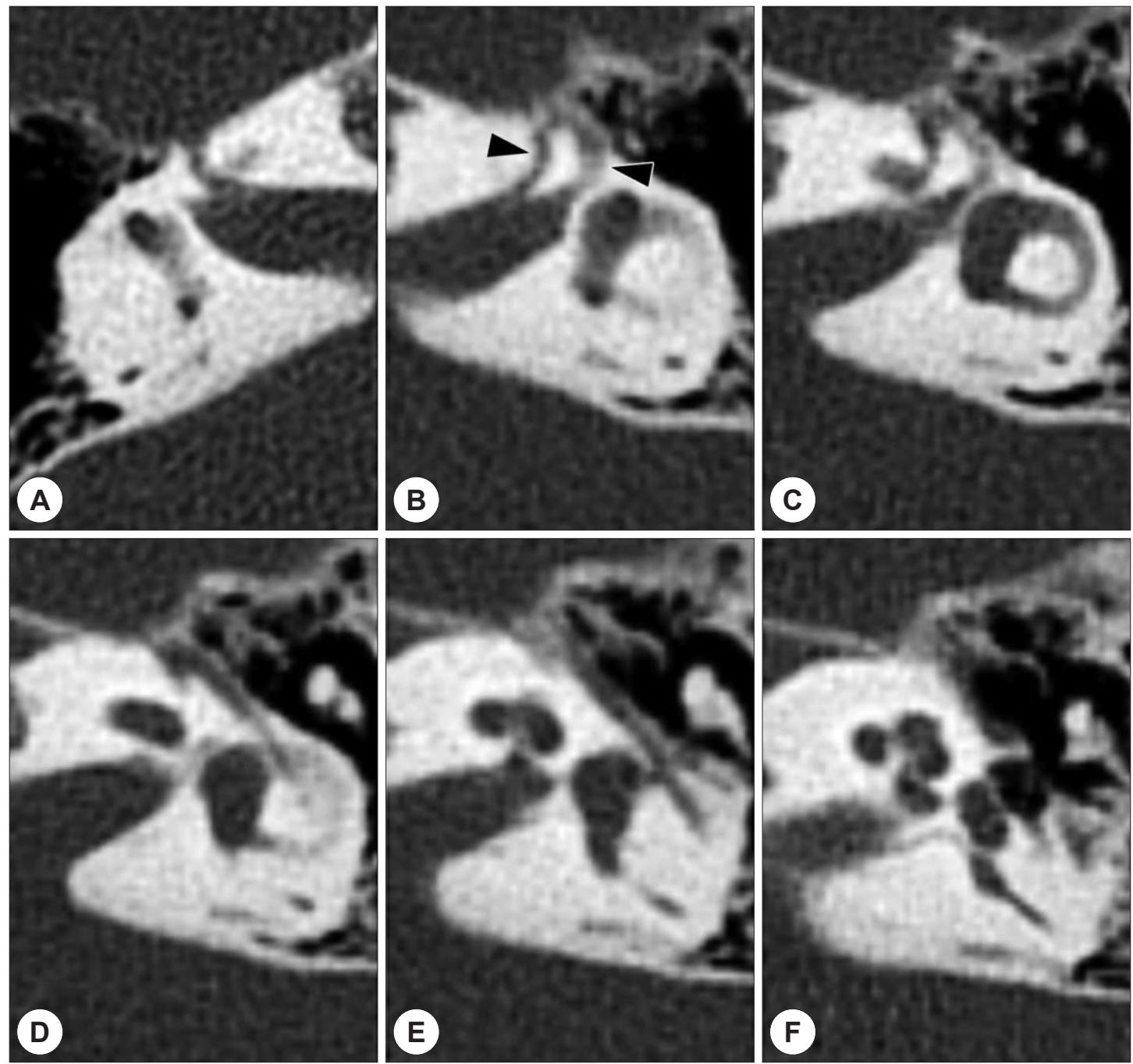

Fig. 1. Axial images on high-resolution computed tomography of the temporal bone. A : Normal course of right fallopian canal. B-F : Bifurcated course of labyrinthine segment of left facial nerve, which merged together into the genu (arrow heads). E : They also showed the narrow bony cochlear nerve canal on left side. 
cation system) workstation (Macroview ; Infinitt, Seoul, Korea), several dimensions of bifurcated labyrinthine segments of fallopian canal (Fig. 3). The length of front labyrinthine segment was $4.42 \mathrm{~mm}$ and axial diameter was variable along its course $(0.63$ to $0.88 \mathrm{~mm})$. The

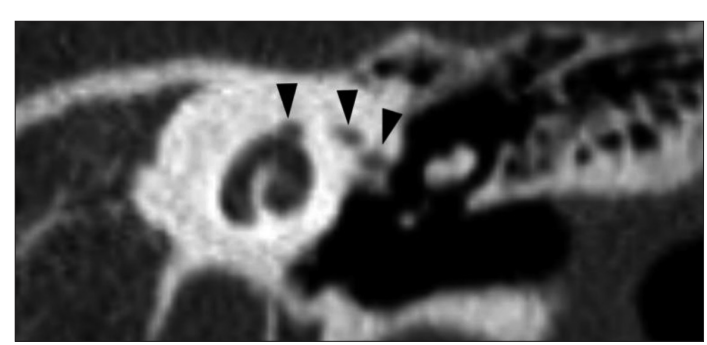

Fig. 2. Coronal images on high-resolution computed tomography of the temporal bone. On coronal images, normal shape of proximal tympanic segment and distal labyrinthine segment of the facial nerve are visualized superior to the cochlea, appearing like "snake eyes" or "snail eyes". However, this coronal images shows three eyes (arrow heads) superior to the cochlea.
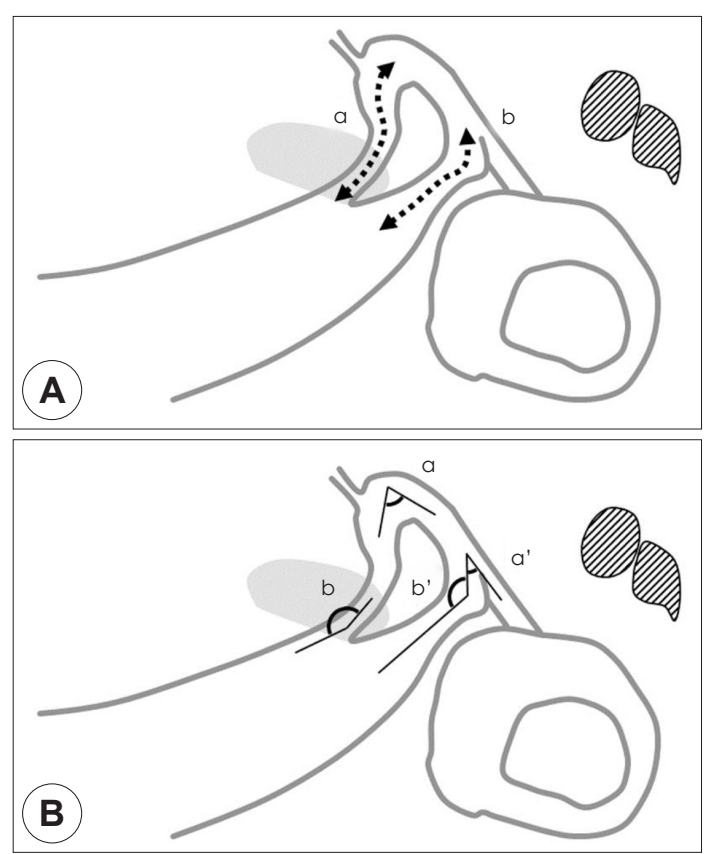

Fig. 3. Schematic diagram to illustrate how to measure the dimension of bifurcated facial nerve. $A$ : $a=a$ length of front labyrinthine segment and $b=a$ length of rear one. $B: a, a^{\prime}=$ angle between labyrinthine and tympanic segments ; b, b'=angle between internal auditory canal and labyrinthine segments. Gray shadow shows a basal turn of cochlea and two hatched shadows shows malleus and incus. length of rear one was $4.02 \mathrm{~mm}$ and axial diameter was variable along its course ( 0.88 to $1.58 \mathrm{~mm})$. For front labyrinthine segments of fallopian canal, angle between internal auditory canal and labyrinthine segments was 134 degree and that between labyrinthine and tympanic segments was 37 degree. For rear one, angles between internal auditory canal and labyrinthine segments and between labyrinthine and tympanic segments were 103 and 23 degree, respectively. The diameter of bony cochlear nerve canal was measured manually at the mid-modiolar level and $0.39 \mathrm{~mm}$ in ipsilateral and $1.81 \mathrm{~mm}$ in contralateral cochleas.

Considering previous report of a case with bifurcation of the labyrinthine segment accompanied by Klippel-Feil syndrome, she got examination of pediatrician and there was no abnormality of spine or palate.

Considering unilateral sensorineural hearing loss (four-frequency pure-tone average $=66 \mathrm{~dB} \mathrm{HL}$, puretone average of 2,3 , and $4 \mathrm{kHz}=68 \mathrm{~dB} \mathrm{HL}$, speech recognition threshold of $75 \mathrm{~dB} \mathrm{HL}$ ), left hearing aid of completely-in-canal (CIC) type was tried at first. However, her audibility was not improved maybe due to too poor speech discrimination, she thought that a hearing aid was annoying, and she denied a hearing aid finally after 1 month-wearing. Because the duration of hearing loss was long (maybe 9 years) and her parents did not want any surgery, cochlear implant was not considered. Contralateral routing of signals (CROS) hearing aid was considered but not adopted. At present, further hearing rehabilitation was not planned and regular audiologic tests was scheduled.

\section{Discussion}

Various anomalies of the fallopian canal have been reported previously. The most common variation is a congenital bony dehiscence of the fallopian canal. Baxter $^{5)}$ reported the incidence of bony dehiscent fallopian canal was $55 \%$ in otherwise normal temporal bones. Moreano et al. ${ }^{6}$ analyzed 1,000 temporal bones with microscopic examination and reported that at least one facial canal dehiscence was found in 56\% and bi- 
lateral prevalence was $76.3 \%$. Due to its high prevalence, this anomaly was even regarded as normal variation. $^{5-7)}$

Bifurcation or trifurcation of the fallopian canal is rare congenital anomaly. While any segment of the facial nerve can be involved in this variation, a tympanic segment is known as the most common portion, especially at the anterior or superior area of oval window. ${ }^{2-4)}$ Bifurcation of mastoid segment is also previously reported. ${ }^{8,9)}$ However, bifurcation of the labyrinthine segment has been seldom reported. ${ }^{10)}$ Glastonbury et al. ${ }^{2)}$ reported a case of 6-year-old girl with bilateral mixed hearing loss showing unilateral bifurcation of the labyrinthine segment as well as dilated posterior semicircular canal. Tehrani et al. ${ }^{11)}$ also reported a case of 2 years-old girl with Klippel-Feil syndrome, whose CT demonstrated unilateral bifurcation of the labyrinthine segment of the facial nerve as well as other intratemporal anomalies including common cavity anomalies and narrow internal acoustic canals of both ears. Jin et al. ${ }^{12)}$ reported a case showing the bifurcation of the labyrinthine segment of unilateral facial nerve without accompanying middle and inner ear malformation. They analyzed 45 ears of 24 cases and classified the variations in the labyrinthine segment of the facial nerve into 5 types ; 1) bony dehiscence in the geniculate fossa $(55.5 \%), 2)$ anteromedial displacement of its course at the beginning site $(60.0 \%), 3)$ enlargement of the first genu $(66.7 \%), 4)$ increase of its length (66.7\%), and 5) its bifurcation (2.2\%).

In our case, bifurcation of the labyrinthine segment was found only unilaterally. CT showed that two branches of the facial nerve came out from internal auditory canal with separate bony canals at the labyrinthine segment. Glastonbury et al. ${ }^{2)}$ pointed out that one branch of bifurcation is the facial nerve itself and the other is thought to be the nervus intermedius. Jin et al. ${ }^{12)}$ also stated that the latter nerve is more slender, but the two bony canals have similar diameter. According these statements, we assumed that anterior canal of bifurcation was for the nervus intermedius and posterior one was for the facial nerve. ${ }^{13)}$
Abnormal bifurcation of the facial nerve may occur at the early embryonic stage but we know little about the mechanism of facial nerve bifurcation. Because facial and acoustic components develop separately, this bifurcation malformation of the facial nerve is not necessarily accompanied by other malformations of inner ear anomaly. However, our case was accompanied by ipsilateral narrow bony cochlear nerve canal. The diameter of bony cochlear nerve canal in this case was $0.39 \mathrm{~mm}$ in the same side as bifurcated facial nerve, which suggests that cochlear nerve may be hypoplastic. ${ }^{14)}$ Several studies showed narrowed or stenotic bony cochlear nerve canal can cause congenital sensorineural hearing loss. ${ }^{14,15)}$ Lim et al. ${ }^{15)}$ stated that stenotic bony cochlear nerve canal is a potential cause of unilateral sensorineural hearing loss. Because the bony cochlear nerve canal encases the cochlear nerve, it has been known that its stenosis suggests the marker of anatomic or functional deficiency of the cochlear nerve. There was no literature reporting the epidemiology of simultaneous expression of stenotic bony cochlear nerve canal and bifurcated facial nerve.

Using high resolution $\mathrm{CT}$, we present that the facial nerve were duplicated at the labyrinthine segment and they merged together at the genu in our case, which is shown clearly in Fig. 1B. However, CT do not present any information of the bifurcated nerves themselves because CT image shows only bony fallopian canal in the temporal bone. When CT reveals abnormal course of a fallopian canal, it is necessary to check out MRI to find out detail information of facial nerve.

\section{Conclusion}

We described a case of 9-year old girl with sensorineural hearing loss and bifurcation of labyrinthine segment of the facial nerve. Structural anomaly of facial nerve can be accompanied by the middle or inner ear malformations. Therefore, it is necessary to evaluate $\mathrm{CT}$ images in the patients with congenital hearing loss. This can be helpful to make correct diagnosis and to avoid potential damage during the surgery including 
cochlear implantation.

\section{REFERENCES}

1) Romo LV, Curtin HD. Anomalous facial nerve canal with cochlear malformations. AJNR Am J Neuroradiol 2001;22 (5):838-44.

2) Glastonbury CM, Fischbein NJ, Harnsberger HR, Dillon WP, Kertesz TR. Congenital bifurcation of the intratemporal facial nerve. AJNR Am J Neuroradiol 2003;24(7):1334-7.

3) Celin SE, Wilberger JE, Chen DA. Facial nerve bifurcation within the internal auditory canal. Otolaryngol Head Neck Surg 1991;104(3):389-93.

4) Nager GT. Pathology of the ear \& temporal bone. Philadelphia: Lippincott Williams \& Wilkins;1993. p.147-64.

5) Baxter A. Dehiscence of the fallopian canal. J Laryngol Otol 1971;85(6):587-94.

6) Moreano EH, Paparella MM, Zelterman D, Goycoolea MV. Prevalence of facial canal dehiscence and of persistent stapedial artery in the human middle ear: a report of 1000 temporal bone. Laryngoscope 1994;104(3 Pt 1):309-20.

7) Jahrsdoerfer RA. The facial nerve in congenital middle ear malformations. Laryngoscope 1981;91(8):1217-25.

8) Jakkani RK, Ragavendra KI, Karnawat A, Vittal R, Kumar AD. Congenital duplication of mastoid segment of facial nerve: a rare case report. Indian J Radiol Imaging 2013;23 (1):35-7.
9) Kim SR, Jung H. Bilateral bifurcation of the mastoid segment of the facial nerve. Korean J Otolaryngol-Head Neck Surg 2005;48(6):804-6.

10) Nager GT, Proctor B. The facial canal: normal anatomy, variations and anomalies. II. Anatomical variations and anomalies involving the facial canal. Ann Otol Rhinol Laryngol Suppl 1982;97:45-61.

11) Tehrani SJT, Faizah MZ, Kew TY, Abdullah A. Facial canal bifurcation with inner ear anomalies in a case of Klippel-Feil syndrome: a case report. Int J Pediatr Otorhinolaryngol Extra 2013;8(2):32-5.

12) Jin $A, X u P, Q u F$. Variations in the labyrinthine segment of facial nerve canal revealed by high-resolution computed tomography. Auris Nasus Larynx 2018;45(2):261-4.

13) Som PM, Surtin HD, Liu K, Maffe MF. Current embryology of the temporal bone, Part II: the middle and external ears, the statoacoustic and facial nerves, and when things go developmentally wrong. Neurographics 2016;6:332-49.

14) Tahir E, Bajin MD, Atay G, Mocan BO, Sennaroglu L. Bony cochlear nerve canal and internal auditory canal measures predict cochlear nerve status. J Laryngol Otol 2017;131(8): 676-83.

15) Lim CH, Lim JH, Kim DY, Choi HS, Lee DH, Kim DK. Bony cochlear nerve canal stenosis in pediatric unilateral sensorineural hearing loss. Int J Pediatr Otorhinolaryngol 2018;106:72-4. 